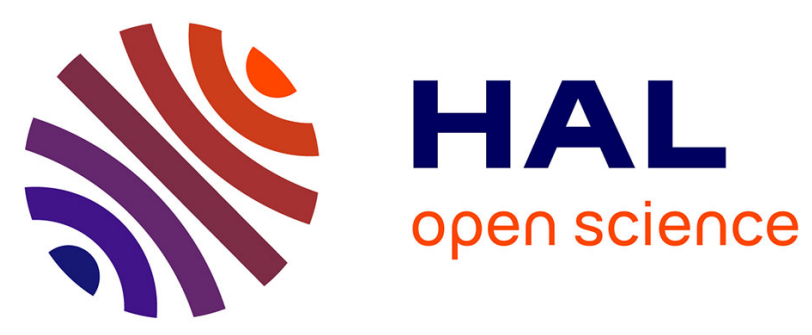

\title{
Gene expression profiling of response to mTOR inhibitor everolimus in pre-operatively treated post-menopausal women with oestrogen receptor-positive breast cancer
}

Vicky S. Sabine, Andrew H. Sims, E. Jane Macaskill, Lorna Renshaw, Jeremy S. Thomas, J. Michael Dixon, John M. S. Bartlett

\section{To cite this version:}

Vicky S. Sabine, Andrew H. Sims, E. Jane Macaskill, Lorna Renshaw, Jeremy S. Thomas, et al.. Gene expression profiling of response to mTOR inhibitor everolimus in pre-operatively treated postmenopausal women with oestrogen receptor-positive breast cancer. Breast Cancer Research and Treatment, 2010, 122 (2), pp.419-428. 10.1007/s10549-010-0928-6 . hal-00537244

\author{
HAL Id: hal-00537244 \\ https://hal.science/hal-00537244
}

Submitted on 18 Nov 2010

HAL is a multi-disciplinary open access archive for the deposit and dissemination of scientific research documents, whether they are published or not. The documents may come from teaching and research institutions in France or abroad, or from public or private research centers.
L'archive ouverte pluridisciplinaire HAL, est destinée au dépôt et à la diffusion de documents scientifiques de niveau recherche, publiés ou non, émanant des établissements d'enseignement et de recherche français ou étrangers, des laboratoires publics ou privés. 


\title{
Gene expression profiling of response to $\mathrm{mTOR}$ inhibitor everolimus in pre-operatively treated post-menopausal women with oestrogen receptor-positive breast cancer
}

\author{
Vicky S. Sabine $\cdot$ Andrew H. Sims $\cdot$ E. Jane Macaskill • \\ Lorna Renshaw • Jeremy S. Thomas • \\ J. Michael Dixon · John M. S. Bartlett
}

Received: 19 January 2010/Accepted: 28 April 2010/Published online: 18 May 2010

(C) Springer Science+Business Media, LLC. 2010

\begin{abstract}
There is growing evidence that uncontrolled activation of the PI3K/Akt/mTOR pathway contributes to the development and progression of breast cancer. Inhibition of this pathway has antitumour effects in preclinical studies and efficacy in combination with other agents in breast cancer patients. The aim of this study is to characterise the effects of pre-operative everolimus treatment in primary breast cancer patients and to identify potential molecular predictors of response. Twenty-seven patients with oestrogen receptor (ER)-positive breast cancer completed 11-14 days of neoadjuvant treatment with 5-mg everolimus. Core biopsies were taken before and after treatment and analysed using Illumina HumanRef-8 v2 Expression BeadChips. Changes in proliferation (Ki67) and phospho-AKT were measured on diagnostic core biopsies/resection samples embedded in paraffin by immunohistochemistry to determine response to treatment. Patients that responded
\end{abstract}

Electronic supplementary material The online version of this article (doi:10.1007/s10549-010-0928-6) contains supplementary material, which is available to authorized users.

V. S. Sabine · E. J. Macaskill · J. M. S. Bartlett (ه)

Endocrine Cancer Group, University of Edinburgh Cancer Research Centre, Institute of Genetics \& Molecular Medicine,

Western General Hospital, Crewe Road South, Edinburgh EH4

2XR, UK

e-mail: John.bartlett@ed.ac.uk

\footnotetext{
A. H. Sims

Applied Bioinformatics of Cancer Group, Edinburgh Breakthrough Unit, University of Edinburgh Cancer Research Centre, Institute of Genetics \& Molecular Medicine, Western General Hospital, Crewe Road South, Edinburgh EH4 2XR, UK

E. J. Macaskill · L. Renshaw - J. S. Thomas - J. M. Dixon Edinburgh Breast Unit, Institute of Genetics \& Molecular Medicine, University of Edinburgh, Western General Hospital, Crewe Road South, Edinburgh EH4 2XR, UK
}

to everolimus treatment with significant reductions in proliferation (fall in \% Ki67 positive cells) also had significant decreases in the expression of genes involved in cell cycle $(P=8.70 \mathrm{E}-09)$ and $\mathrm{p} 53$ signalling $(P=0.01)$ pathways. Highly proliferating tumours that have a poor prognosis exhibited dramatic reductions in the expression of cell cycle genes following everolimus treatment. The genes that most clearly separated responding from nonresponding pre-treatment tumours were those involved with protein modification and dephosphorylation, including DYNLRB2, ERBB4, PTPN13, ULK2 and DUSP16. The majority of ER-positive breast tumours treated with everolimus showed a significant reduction in genes involved with proliferation, these may serve as markers of response and predict which patients will derive most benefit from mTOR inhibition.

Keywords mTOR - Everolimus - Breast cancer . Pre-operative treatment $\cdot$ Gene expression

\section{Introduction}

The PI3K/AKT/mTOR (mammalian Target Of Rapamycin) pathway plays a central role in multiple cellular functions including proliferation, growth, survival and metabolism (reviewed in [1]). There is growing evidence that this pathway is frequently deregulated during tumourigenesis, via genetic and epigenetic alterations, contributing to the development and progression of human cancers, including breast cancer (reviewed by [1]). Deregulation includes activating mutations in the PIK3CA (phosphoinositide-3kinase, catalytic, alpha polypeptide) gene which have been described in 16-40\% of breast cancers studied [2, 3], loss of PTEN expression in $37-48 \%$ of breast cancers $[4,5]$ and 
high expression levels of AKT isoforms in approximately $27 \%$ of breast cancers $[6,7]$. Taken together, these studies implicate activation of the PI3K/AKT/mTOR pathway in breast cancer and there is evidence to suggest that this may lead to endocrine resistance $[6,8]$. Components of this pathway are attractive targets for novel anticancer agents, including mTOR a serine/threonine kinase belonging to the phosphatidylinositol-3OH kinase-related kinase (PIKK) family (reviewed in [9]).

Rapamycin down-regulates signalling via the PI3K/Akt/ mTOR pathway by inhibition of mTOR activity, resulting in decreased tumour growth (reviewed by [9]). Everolimus (RAD001, Novartis, Basel, Switzerland), a novel rapamycin derivative, is a potent mTOR inhibitor that does not share the problems of poor solubility and chemical stability of rapamycin [10]. Everolimus displays direct inhibitory effects on breast cancer cell growth and proliferation in preclinical models [11-13]. Clinical trials, including Phase-II trials in breast cancer, have tested the efficacy of everolimus treatment either as a monotherapy or in combination with letrozole. Everolimus given as a single agent in patients with advanced cancer $(n=55)$, produced clinical benefit in $7 \%$ of patients, which included disease stabilisation in two breast cancer patients for $>5$ months [14]. In combination with letrozole, everolimus produced one complete response and six stable disease responses $>6$ months in patients with advanced breast cancer ( $n=18)$ [15] and in the neoadjuvant setting, this combination increased the efficacy of letrozole in newly diagnosed breast cancer patients $(n=138)$ [16]. In the first clinical study of everolimus administered as a single preoperative agent in primary breast cancer patients, everolimus treatment significantly reduced proliferation (Ki67) and mTOR pathway activation [17]. This is in agreement with a previously reported neoadjuvant study in which everolimus (see above), in combination with letrozole, demonstrated a decrease in Ki67 almost double that of the letrozole plus placebo group [16]. This is potentially important as in the neo-adjuvant setting changes in Ki67 have been correlated to long-term outcome [18, 19]. Although results from these clinical trials are encouraging, there is a need to identify biomarkers for selecting the subset of patients that may benefit from an mTOR inhibitor $[20,21]$.

Gene expression profiling has been widely used in the breast cancer field for tumour classification and to predict prognosis [22]. More recently, microarrays have been used to characterise gene expression changes which occur during treatment in vivo, which may be predictive of treatment benefit $[23,24]$. Here, we report the first characterisation of the effects of single agent everolimus treatment on tumour gene expression, from the pre-operative study of everolimus in early breast cancer patients [17]. The aim is to assess whether a gene expression profile could be determined which will predict which patients will respond to everolimus.

\section{Methods}

Patients

Ethical approval for this study was obtained from Northern and Yorkshire MREC (MREC reference 04/MRE03/89). All patients gave informed consent. A total of 32 postmenopausal women diagnosed with operable ER-positive early breast cancer were recruited to receive $5 \mathrm{mg}$ of everolimus pre-operative treatment daily for 14 days prior to primary surgery [17]. Of those recruited to the study, 27 patients completed $\geq 11$ days everolimus treatment (4 withdrew and took $<10$ days of treatment and 1 did not start medication; Fig. 1a). As a single dose of everolimus leads to S6K1 inhibition for $>72 \mathrm{~h}$ in tumours [25, 26], patients treated with everolimus for 11-13 days were included in this study.

\section{RNA extraction and microarray hybridisation}

Paired biopsies were taken at diagnosis and at surgery; half of the tissue was immediately frozen in liquid nitrogen and stored at $-196^{\circ} \mathrm{C}$. Frozen sections were removed, sectioned and stained with haematoxylin and eosin to assess tumour content. Approximately 100-mg tissue from preand post-treatment biopsies from 27 patients who completed everolimus treatment were placed in RNAlater ${ }^{\circledR}$ ICE (Ambion, Warrington, United Kingdom) overnight at $-20^{\circ} \mathrm{C}$ prior to RNA extraction using the RNeasy Mini Kit, including RNase-Free DNase treatment (Qiagen, Crawley, United Kingdom). Aliquots of RNA were analysed by electrophoresis and quantified on a Bioanalyser 2100 (G2938c, Agilent Technologies, Stockport, United Kingdom). 100-ng RNA per patient was amplified and biotinylated using Illumina ${ }^{\circledR}$ TotalPrep RNA Amplification Kit (Ambion) and quantified on a Bioanalyser 2100. Highquality labelled cRNA, from samples with $>40 \%$ tumour content [27] was available from 24 matched pre- and posttreatment sample pairs. 750-ng cRNA per sample was hybridized to Illumina HumanRef-8 v2 Expression BeadChip in duplicate (Illumina, Cambridge, United Kingdom) using Whole-Genome Expression Direct Hybridisation kit (Illumina) and scanned with a BeadStation 500G $\times$ (Illumina). Universal Human Reference RNA (UHRR; Stratagene, Stockport, United Kingdom) was added to each BeadChip to assess inter-chip and inter-run variation. Illumina gene expression data were obtained for 21 matched biopsies and 23 pre-treatment samples in duplicate. 
A

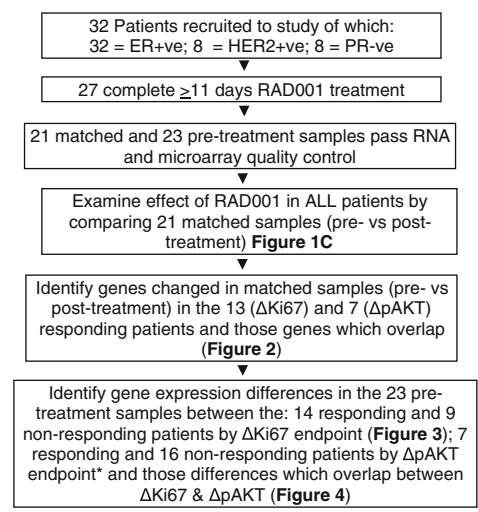

B
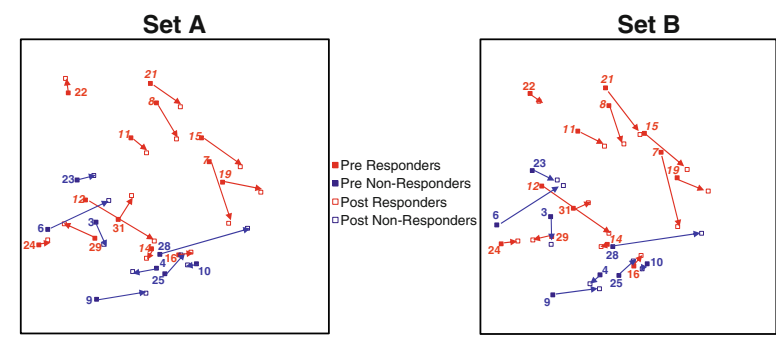

C

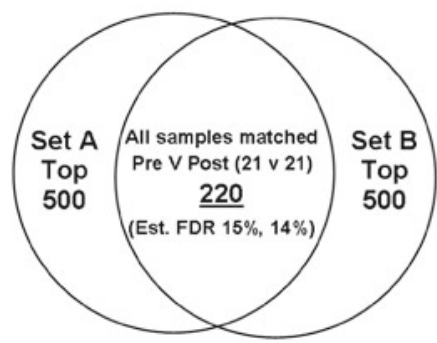

Fig. 1 Response following everolimus treatment in all tumours. a Flow-chart of gene expression analysis performed on samples. Patients defined as responders demonstrated significant (95\% confidence interval) fall in percentage of Ki67 positive cells ( $\Delta \% \mathrm{Ki} 67)$ or cytoplasmic pAKT expression $(\Delta \% \mathrm{pAKT}) . * 7$ patients responding by pAKT endpoint are all patients responding by Ki67 endpoint. b Overall transcriptome differences before and after treatment. Multidimensional scaling plot which clusters the most similar samples together based upon overall gene expression profile. The two plots ('A' and 'B') represent the 1st and 2 nd replicate samples. Pre-treatment samples are represented with filled symbols and post-treatment samples with open symbols. Red represents responding patients (by significant fall in Ki67) and blue represents non-responding patients. Arrows indicate the transition from pre- to post-treatment samples and numbers relate to patient numbers. $\mathbf{c}$ Venn diagram displaying the number of consistently differentially expressed probes between ' $\mathrm{A}$ ' and 'B'. Underlined value represents the intersection between the top 500 most differentially expressed genes from duplicate matched samples. $F D R$ false discovery rate, Est. estimated. See supplementary file 1 for full gene lists of changed, responding and non-responding genes

Immunohistochemistry and responder classification

Tissue was also embedded in paraffin for the analysis of biological response markers by immunohistochemistry, including change in proliferation (Ki67) and cytoplasmic pAKT as described previously [28, 17].
Analysis of variance (ANOVA) was performed to determine differences between those that had a marked reduction in Ki67, 'responders' (R), and those who did not, 'non-responders' (NR). Estimations of 'responders' and 'non-responders' were based upon dual observer analysis of Ki67 staining, the $95 \%$ confidence interval for the mean difference in Ki67 counts between two observers was taken as the minimum difference which could be regarded as a change in Ki67 status between pre- and post- treatment samples [29]. Due to the non-normal distribution of the data, Ki67 scores were transformed on the log scale prior to analysis. The change between pre- and post-treatment scores for each patient was calculated as the difference in the transformed scores.

Patients were classified into 13 matched (14 pre-treatment) responders defined as having a significant $(95 \%$ confidence interval) fall in the percentage of Ki67 positive cells $(\Delta \% \mathrm{Ki} 67)[28,17]$; and 7 matched (7 pre-treatment) responders defined by a significant $(95 \%$ confidence interval) fall in cytoplasmic pAKT expression $(\Delta \% \mathrm{pAKT})$ [28, 17]; the remaining patients were considered as nonresponders.

\section{Statistical methods}

Gene expression changes were compared before and after everolimus treatment and between responders and nonresponders using Bioconductor [30] programs implemented in the statistical programming language, $\mathrm{R}$ [31]. Illumina probe profile expression data were normalised using quantile normalisation within the beadarray package [32] and corrected for batch processing effects using the combat tool [33]. Consistently differentially expressed probes and predicted false discovery rate (FDR) were identified using the pair-wise Significance Analysis of Microarrays (SAM) method [34], implemented with the siggenes package. Cross validation and misclassification rate were assessed using Prediction Analysis of Microarrays (PAM), implemented using the pamr package [35]. Figure 1a summarises the comparisons performed between pre- and post-treatment for responding and non-responding samples. An alternative approach used to look at the effect of everolimus was to compare the relative change in gene expression of each probe calculated between the duplicate pre- and posttreatment samples and the mean of the four values calculated. Centred average linkage clustering was performed using the Cluster [36] and TreeView programs as described previously [37]. The DAVID program was used to identify over-represented pathways from lists of differentially expressed genes. All raw gene expression files and clinical annotation are publicly available from the caBIG supported Edinburgh Clinical Research Facility Data Repository (https://catissuesuite.ecmc.ed.ac.uk/caArray). 


\section{Results}

Pathways differentially expressed after everolimus treatment

Subtle inter-run variations on each Illumina HumanRef- 8 v2 BeadChip were identified using the UHRR, these were thoroughly evaluated in a parallel study [38] and minimised using the ComBat method [33]. The 21 pairs of matched biopsies were analysed in duplicate (Set A and Set B) before and after treatment with everolimus. The overall transcriptomes of these two sets are similar as the positions of duplicate pre- and post-treatment samples are largely consistent and the post-treatment samples are generally to the right of the pre-treatment samples for the majority of patients (Fig. 1b).

The 500 most consistently differentially expressed probes following everolimus treatment in all matched tumours were identified in Set A and Set B separately using SAM analysis. Of the 500 probes from each set, only 220 were common with estimated FDRs of 15 and 14\% (Fig. 1c), clearly demonstrating the value of using technical replicates. The functional (KEGG) pathways determined to be most associated with everolimus treatment when all tumours were analysed together were the complement and coagulation cascades $(P=0.002$; predicted FDR $=1.99 \%$; Table 1$)$.

Table 1 KEGG pathways that were over-represented by the seven lists of significantly differentially expressed probes (listed in Supplementary file 1)

\begin{tabular}{|c|c|c|c|}
\hline Pathway & Genes & $\mathrm{p}$ val & FDR \\
\hline \multicolumn{4}{|c|}{ Pathways differentially expressed following RAD001 treatment (all matched tumours) } \\
\hline MAPK signalling pathway & FOS, DUSP1, MAP4K4, JUN, PDGFRB, FGF7, MAP3K3, CD14 & 0.039 & 39.3 \\
\hline Axon guidance & FYN, CXCL12, EPHA2, SEMA4D, SEMA3A & 0.071 & 60.4 \\
\hline $\begin{array}{l}\text { Complement and coagulation } \\
\text { cascades }\end{array}$ & CFH, SERPING1, C1S, C1R, BDKRB1, C3 & 0.002 & 1.99 \\
\hline $\begin{array}{l}\text { Leukocyte transendothelial } \\
\text { migration }\end{array}$ & ITGAL, CXCL12, JAM3, MMP2, CD99 & 0.055 & 51.0 \\
\hline \multicolumn{4}{|c|}{ Pathways differentially expressed in 13 responding matched tumours (assessed by $\Delta \% \mathrm{Ki} 67$ ) } \\
\hline p53 signalling pathway & CDK2, CDC2, CCNE2, RRM2, IGFBP3 & 0.010 & 12.5 \\
\hline Cell cycle & $\begin{array}{l}\text { ANAPC11, CDK2, CDC2, MCM7, E2F2, PTTG1, RBL1, CCNA2, MCM4, PCNA, MCM2, } \\
\text { CCNE2, YWHAE }\end{array}$ & $\begin{array}{l}8.7 \mathrm{E}- \\
9\end{array}$ & $\begin{array}{l}1.1 \mathrm{E}- \\
5\end{array}$ \\
\hline Pyrimidine metabolism & DTYMK, TYMS, NME1, RRM2, PRIM1 & 0.024 & 26.6 \\
\hline \multicolumn{4}{|c|}{ Pathways differentially expressed in 8 non-responding matched tumours (assessed by $\Delta \% \mathrm{Ki} 67$ ) } \\
\hline $\begin{array}{l}\text { B cell receptor signalling } \\
\text { pathway }\end{array}$ & FOS, NFATC1, PIK3CD & 0.059 & 53.3 \\
\hline VEGF signalling pathway & NFATC1, PTGS2, PIK3CD & 0.069 & 59.4 \\
\hline Acute myeloid leukaemia & PIM1, TCF7L2, PIK3CD & 0.047 & 45.7 \\
\hline Colorectal cancer & FOS, FZD9, TCF7L2, PIK3CD & 0.016 & 18.1 \\
\hline Wnt signalling pathway & FZD9, NFATC1, DKK1, TCF7L2 & 0.066 & 57.4 \\
\hline \multicolumn{4}{|c|}{ Pathways differentially expressed in 7 responding matched tumours (assessed by $\Delta \%$ pAKT) } \\
\hline p53 signalling pathway & RRM2B, CDC2, RFWD2 & 0.084 & 66.5 \\
\hline Pyrimidine metabolism & RRM2B, ITPA, POLR2F, POLD2 & 0.024 & 26.1 \\
\hline Purine metabolism & RRM2B, ITPA, POLR2F, POLD2 & 0.083 & 66.0 \\
\hline \multicolumn{4}{|c|}{ Pathways differentially expressed in 14 non-responding matched tumours (assessed by $\Delta \%$ pAKT) } \\
\hline ErbB signalling pathway & ABL2, NCK2, JUN, PIK3CD & 0.040 & 40.3 \\
\hline $\begin{array}{l}\mathrm{T} \text { cell receptor signalling } \\
\text { pathway }\end{array}$ & FOS, NCK2, JUN, PIK3CD & 0.05 & 48.6 \\
\hline Arachidonic acid metabolism & PTGIS, PTGS2, PLA2G2A & 0.09 & 68.2 \\
\hline \multicolumn{4}{|c|}{14 Pre-treatment responders vs. 9 pre-treatment non responding tumours (assessed by $\Delta \% \mathrm{Ki} 67$ ) } \\
\hline $\begin{array}{l}\text { Natural killer cell mediated } \\
\text { cytotoxicity }\end{array}$ & IFNAR1, MAPK1, KLRD1, NCR3, NFATC3, PIK3CD, & 0.046 & 44.5 \\
\hline Ubiquitin mediated proteolysis & BIRC3, ITCH, BIRC2, CDC20, CDC34, CBL & 0.049 & 47.4 \\
\hline \multicolumn{4}{|c|}{7 Pre-treatment responders vs. 16 pre-treatment non responding tumours (assessed by $\Delta \%$ pAKT) } \\
\hline mTOR signalling pathway & ULK2, TSC2, VEGFB & 0.095 & 71.3 \\
\hline
\end{tabular}


Genes and pathways differentially expressed following treatment in tumours that are either responsive or non-responsive to everolimus

SAM analysis of the 500 most differentially expressed probes in Sets A and B between the 13 matched pairs of responding tumours defined by change in Ki67 following treatment identified 203 common probes with predicted FDRs of 14 and $12 \%$. SAM analysis of the 500 most differentially expressed probes in Sets A and B between the 7 matched pairs of responding tumours defined by change in pAKT following treatment identified 121 common probes with predicted FDRs of 17 and $14 \%$. There were 22 probes in common using either endpoint, 16 of which were down-regulated in responding tumours (Fig. 2).The KEGG pathways most associated with responding tumours (classified by change in Ki67) were cell cycle $(P=8.70 \mathrm{E}-09$; predicted $\mathrm{FDR}=1.1 \mathrm{E}-05 \%)$ and pyrimidine metabolism $(P=0.024$; predicted $\mathrm{FDR}=$ $26.1 \%$ ) pathways (by pAKT, Table 1 ).

Genes and pathways differentially expressed in pre-treatment samples between tumours responsive and non-responsive to everolimus

The 23 pre-treatment biopsies were analysed in duplicate. SAM analysis of the 500 most differentially expressed probes between the 14 responding and the 9 non-responding pre-treatment tumours, defined by a significant fall Ki67 (95\% confidence interval), identified 248 probes (Supplementary file 1), with predicted FDRs of 50 and $44 \%$, in common between Sets A and B. Hierarchical clustering of these 248 probes revealed two clear clusters of genes (Fig. 3). One cluster is composed of genes associated with the gene ontology (GO) terms such as intracellular transport and protein amino acid dephosphorylation which are largely down-regulated in the responding samples. The second cluster contains genes that are associated with cell cycle and carbohydrate metabolism that are generally up-regulated in responders. These cell cycle and carbohydrate metabolism genes divide the responding cancers into two groups, those that can be separated from the non-responders by the proliferation cluster of genes and those that are separated from the non-responders by the genes associated with intracellular transport and protein dephosphorylation. The responder samples separated by the second cluster of genes are those that are clearly distinct in Fig. 1b in the upper right quarter of the plots of Sets A and B at the unsupervised level. These pre-treatment tumours have significantly greater proliferation (\% Ki67 by IHC) and reduced ER levels (by IHC and gene expression, data not shown), than the remaining samples. Cross-validation using PAM analysis indicated an overall misclassification error of 0.043 , with just one responder predicted as a non-responder. Using the replicate
A

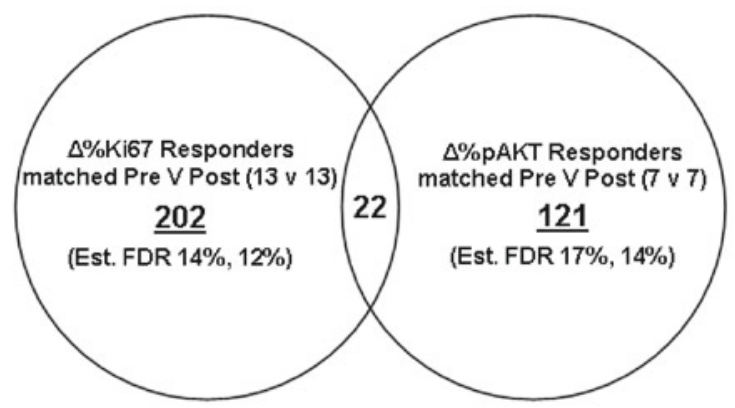

B

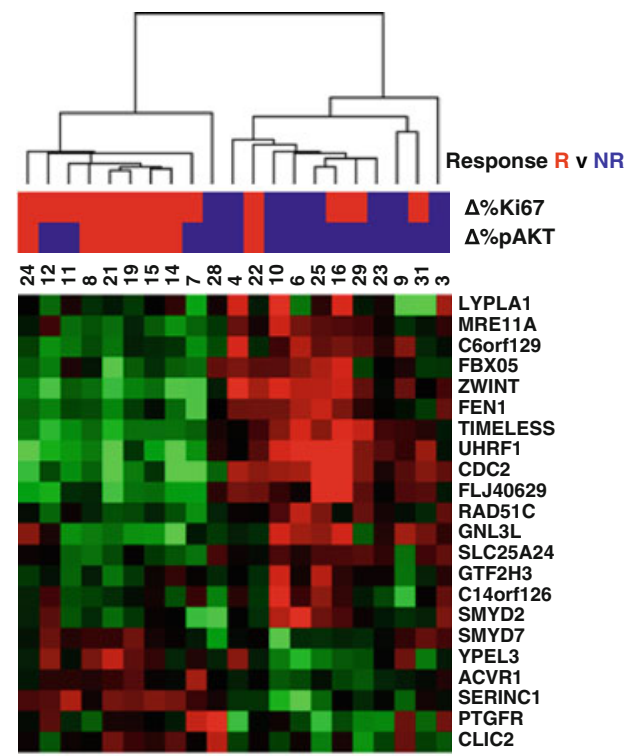

Fig. 2 Genes differentially expressed between matched pre- and post-tumour biopsies that were responsive to everolimus treatment. a Consistently differentially expressed probes between matched 'responders' pre-biopsies versus post-biopsies, defined by proliferation $(\Delta \% \mathrm{Ki} 67)$ and phospho-AKT $(\Delta \% \mathrm{pAKT})$. Underlined values represent the intersection between the top 500 most differentially expressed genes from duplicate matched samples. FDR false discovery rate, Est. estimated. b Hierarchical clustering of 22 probes significantly differentially expressed following treatment in responders measured as a significant reduction in proliferation $(\Delta \% \mathrm{Ki} 67)$ and phospho-AKT ( $\Delta \%$ pAKT). Red and blue bars represent responding (R) and non-responding (NR) patients, respectively. Heatmap represents differential expression of genes (fold changes) in rows and patients in columns (rows) and expression (red $=$ high, green $=$ low) is represented on a relative (mean-centred) scale

datasets as training and test sets was $100 \%$ accurate; however, a fully independent dataset would be required to properly assess the robustness of the signature.

SAM analysis of the 500 most differentially expressed genes between the 7 responding and the 16 non-responding pre-treatment tumours, defined by change in pAKT, identified 238 genes in common, with predicted FDRs of 48 and $56 \%$, between the two sets. Of the 248 (Ki67 response) and 238 (AKT response) probes, 19 genes were found to be present in both probe-lists (Fig. 4a) and the majority are down-regulated in the responding pre-treatment tumours 


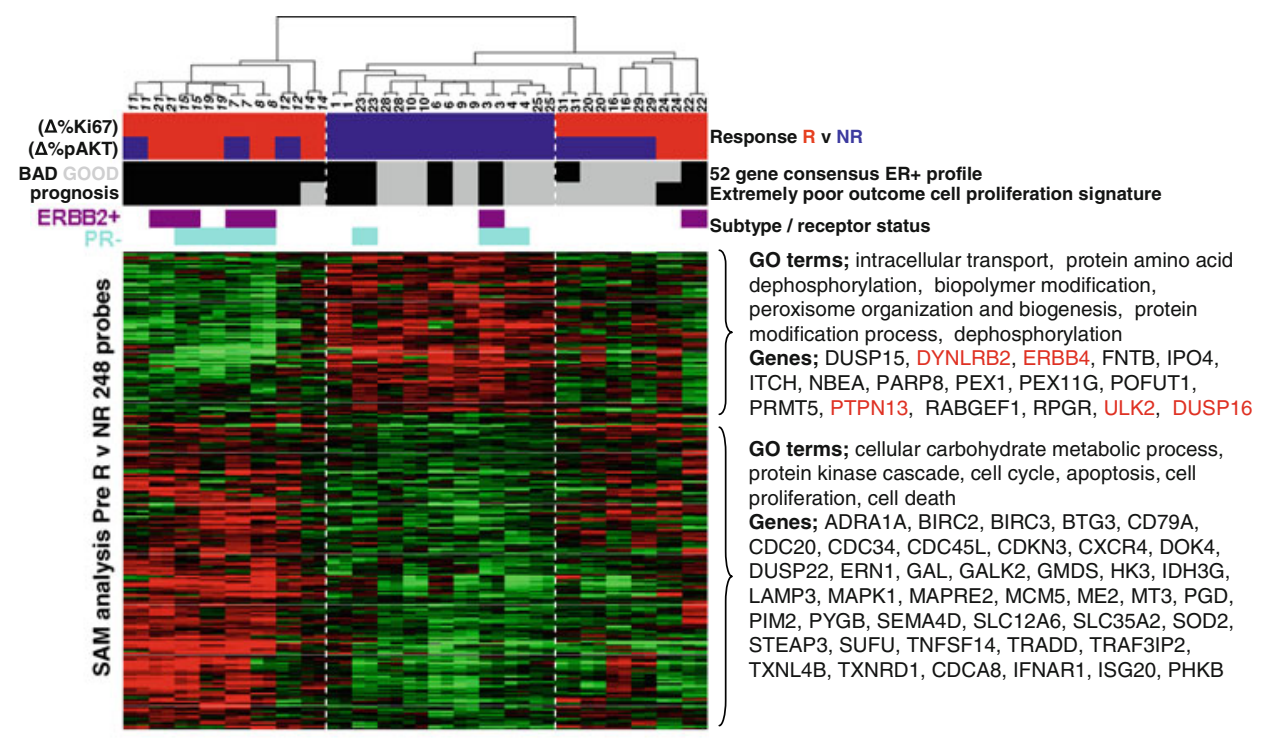

Fig. 3 Hierarchical clustering of 248 differentially expressed probes separating pre-everolimus treatment responding $(\Delta \mathrm{Ki} 67)$ biopsies from the non-responding samples. Red and blue bars represent responding (R) and non-responding (NR) patients, respectively. Grey and black bars signify which tumours have either a good or a bad prognosis based upon the 52-gene consensus classifier for ER-positive tumours [49] and the extremely poor outcome proliferation signature [50]. Light blue and purple bars signify which tumours were PR- and

(Fig. 4b). The KEGG pathway most overrepresented by differentially expressed genes in the pre-treatment biopsies, classified by change in Ki67 was natural killer-cell-mediated cytotoxicity $(P=0.046$; predicted FDR $=44.5)$ and classified by change in pAKT was mTOR signalling pathway $(P=0.095$; predicted $\mathrm{FDR}=71.3)$; the high false discovery rates mean these results should be treated with caution (Table 1).

Analysis of expression of genes in mTOR signalling pathway

Transcripts representing components of the mTOR signalling pathway such as mTOR (FRAP1), Rictor, Raptor and BAD, were not among those most significantly differentially expressed following everolimus treatment (Supplementary file 2). However, expression levels of two probes representing BAD were higher in non-responding tumours before $(P=0.05, P=0.03)$ and after $(P=0.004, P=0.00006)$ treatment than in responding tumours. Intriguingly, expression of FRAP1 probe was higher in post-treatment responding tumours than non-responding tumours $(P=0.01)$.

\section{Discussion}

Following pre-operative treatment of ER positive early breast cancers with single agent everolimus, no simple clear-cut
ERBB2+, respectively. Heatmap represents differential expression of genes (fold changes) in rows and patients in columns (rows) and expression $($ red $=$ high, green $=\mathrm{low})$ is represented on a relative (mean-centred) scale. Genes highlighted in red text were also amongst the 19 differentially expressed probes identified to be differentially expressed between responding and non-responding patients by a significant reduction in both Ki67 and phospho-AKT (see Fig. 4)

response in terms of the genes and pathways altered, was observed when all the tumours (responding and nonresponding) were analysed together. The pathway identified to be the most significantly associated with everolimus treatment in all tumours mapped to complement and coagulation cascades. This may demonstrate an impact of mTOR inhibition on the cell cycle and potential interactions between mTOR inhibition and the immune system. This is in agreement with the clinical results of this study, in that a significant reduction in white cells, neutrophils and platelet count were observed in the patients following everolimus treatment [17].

It was not surprising that genes differentially expressed in the matched responding patients were highly associated with reductions in proliferation and cell cycle genes as a significant change in Ki67 was used as the main basis for defining response. However, 22 common probes were differentially expressed when reduction in both Ki67 and pAKT, were used as the endpoint. These included Timeless, and CDC2. The 'Timeless' gene has been shown previously to be a potential marker of response in tamoxifen-treated post-menopausal patients [39]. These data suggest response by Timeless may not necessarily be treatment-specific. CDC2, whose expression appears to be down-regulated in the responding patients has also been reported to be decreased in B-cell lymphoma cell lines [40] and pancreatic cells [41] after rapamycin treatment.

Transcripts representing components of the mTOR signalling pathway were not among those most significantly 
Fig. 4 Genes differentially expressed in pre-treatment samples between tumours responsive and non-responsive to everolimus. a Consistently differentially expressed probes in pre-treatment biopsies between 'responders' versus 'non-responders', defined by proliferation $(\Delta \% \mathrm{Ki} 67)$ and phospho-AKT ( $\Delta \%$ pAKT). Underlined values represent the intersection between the top 500 most differentially expressed genes from duplicate samples.FDR false discovery rate, Est. estimated. b Hierarchical clustering of 19 probes significantly differentially expressed between responders (red) and nonresponders (blue) measured as a significant reduction in proliferation $(\Delta \% \mathrm{Ki} 67)$ and phospho-AKT $(\Delta \%$ pAKT). Heatmap represents differential expression of genes (fold changes) in rows and patients in columns (rows) and expression (red $=$ high, green $=$ low $)$ is represented on a relative (meancentred) scale
A

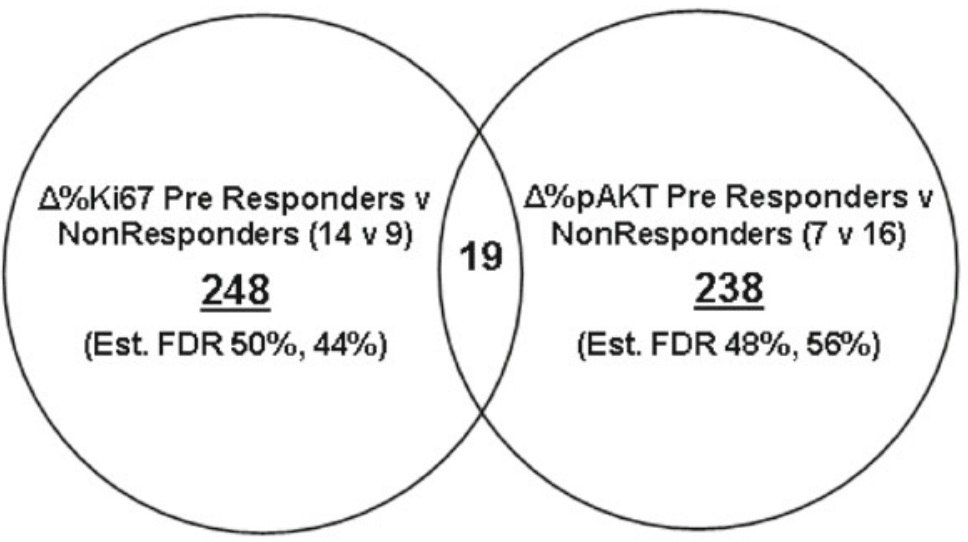

B

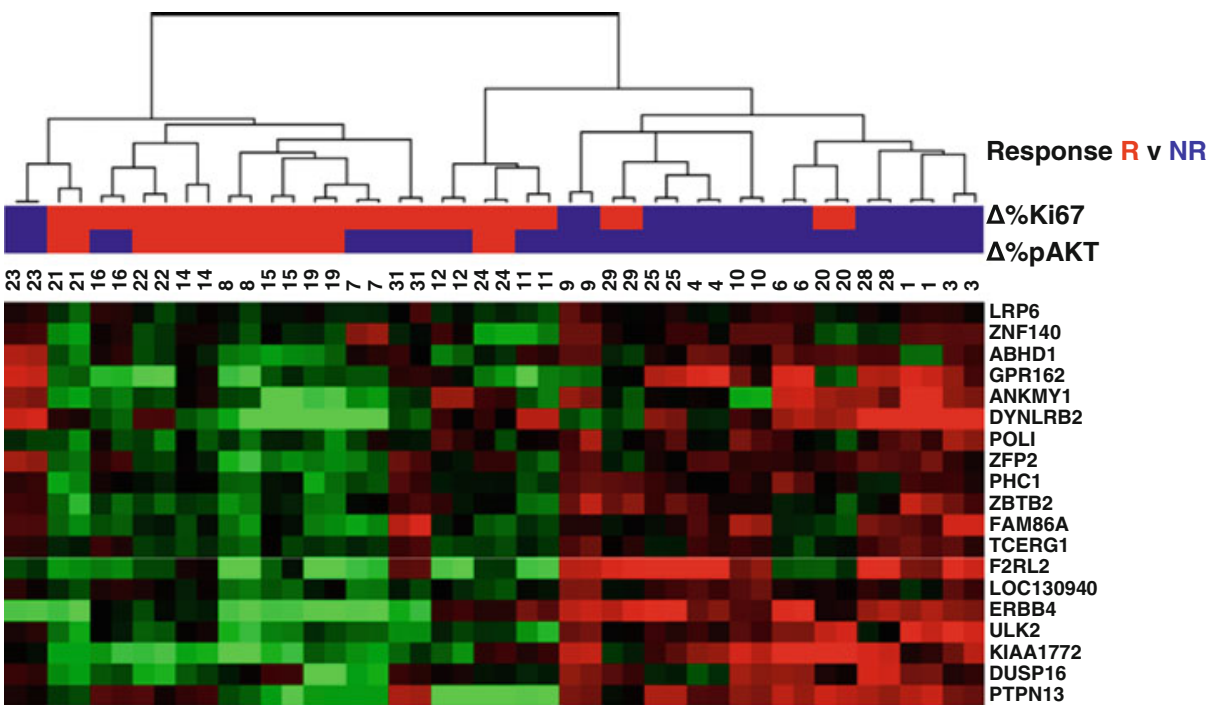

differentially expressed following treatment, suggesting that changes seen at the protein level better characterise changes in the mTOR pathway to everolimus treatment in breast tumours [17]. This is in agreement with our recent report that nuclear expression of pAKT and p-S6k staining was significantly reduced with everolimus treatment in all tumours, although not at all predictive of response [17]. This could be due to post-transcriptional alterations or everolimus affecting alternative pathways to that of mTOR, such as the IGF-1R pathway. What remains to be determined is whether therapeutic inhibitors of mTOR act upon mTORC1 and thus will upregulate Akt pathway, or upon mTORC2 with possible downregulation of the Akt pathway. The study by Macaskill et al. [17] suggests that everolimus downregulates both mTORC1 and mTORC2 in patients that responded to treatment.

Analysis of pre-treatment samples suggests there are two distinct groups of tumours which respond to everolimus and one group that does not. The non-responding tumours had high pre-treatment expression of genes associated with the GO terms 'protein intracellular transport' and 'dephosphorylation' including DYNLRB2, ERBB4, ULK2, and PTPN13, irrespective of whether reduction in Ki67 or pAKT was used as the response endpoint. ERBB4 expression in breast cancers has been regarded previously as a marker for favourable patient prognosis, although controversial exceptions have been reported [42]. Of the responding patients, approximately half had a high pretreatment proliferation determined by Ki67 IHC or by applying the Genomic Grade Index (not shown). Several earlier studies have demonstrated that proliferation and cell cycle genes are strongly prognostic [43], and such genes are strongly represented in the genomic grade index [44], OncotypeDx [45] and Mammaprint [46] molecular profiles. However, our study suggests that highly proliferating tumours with poor prognosis are amongst those that respond to everolimus, at least in the short term. In addition to these highly proliferative tumours, a second group was identified, characterised by low expression of genes associated with the GO terms 'protein intracellular transport' and 'dephosphorylation' including DYNLRB2, ERBB4, ULK2 and PTPN13 (see above). 
The most consistently differentially expressed genes (with the lowest predicted FDRs) were seen for pre- versus post-treatment matched responding samples, supporting the rationale for identifying consistent changes in individuals. Analysis of neoadjuvant letrozole treatment in a previous study also suggested responding tumours have similar, more consistent gene expression profiles, whilst nonresponding (resistant) tumours have multiple patterns of gene changes [24, 47].

This clinical study is one of very few to perform technical replicates on primary samples using Illumina microarray platform. Although the duplicate BeadChips from the same tumours were more similar to each other than different tumours, small variations led to relatively few common differentially expressed genes being identified $(<50 \%)$ between the two sets of BeadChips processed. Using the intersection of two lists of genes from technical replicates may reduce the number of spurious findings that are inevitable in microarray experiments with small sample sizes.

The numbers of patients in this study are too small to feasibly test gene classifiers with robust statistical power. We are unaware of any suitable validation datasets currently available with which to compare our findings. Hence, further investigations must be carried out and we look forward to future studies on mTOR-inhibitors that may be able to validate the results presented here. In particular, it will be interesting to compare the differentially expressed genes identified in this study to those in the phase-II study of everolimus in combination with letrozole [16], once these gene profiles are published. Creighton [48] identified everolimus-sensitive and -insensitive genes induced by Akt in transgenic mice that positively correlated with Akt in human breast tumours, although the everolimus sensitive genes were associated with ER-negative status. A single gene from this signature, Mitochondrial ribosomal protein S7 (MRPS7) was significantly differentially expressed in matched responding tumours in this study.

We have characterised the response to short-term everolimus in primary breast tumours using matched pre- and post-treatment samples. Gene classifiers stratifying patients by their response to everolimus or by their pre-treatment expression profile have been derived and these require further investigation and validation. The study also raises important questions about whether replicate microarrays are warranted and whether protein expression or mRNA changes are the most suitable endpoints for determining response to treatment.

Acknowledgements We would like to acknowledge Oliver Young, Emma Murray, Mary McHugh and Alexey Larionov for tissue banking, Edinburgh Wellcome Trust Clinical Research Facility Genetics Core for processing the BeadChips, and Edinburgh Computer and Data Facility for providing computational support. The research work was supported by Breast Cancer Research \&
Treatment, UK. The clinical study was funded by Novartis Pharma. AHS is funded by Breakthrough Breast Cancer.

Conflict of interest J. Michael Dixon possesses an unrestricted educational grant and honoraria for seminar presentations from Novartis Pharma. All the other authors declare that they have no conflicts of interest.

\section{References}

1. Dillon RL, White DE, Muller WJ (2007) The phosphatidyl inositol 3-kinase signaling network: implications for human breast cancer. Oncogene 26:1338-1345

2. Liedtke C, Cardone L, Tordai A, Yan K, Gomez HL, Figureoa LJ, Hubbard RE, Valero V, Souchon EA, Symmans WF, Hortobagyi GN, Bardelli A, Pusztai L (2008) PIK3CA-activating mutations and chemotherapy sensitivity in stage II-III breast cancer. Breast Cancer Res 10:R27

3. Campbell IG, Russell SE, Choong DY, Montgomery KG, Ciavarella ML, Hooi CS, Cristiano BE, Pearson RB, Phillips WA (2004) Mutation of the PIK3CA gene in ovarian and breast cancer. Cancer Res 64:7678-7681

4. Depowski PL, Rosenthal SI, Ross JS (2001) Loss of expression of the PTEN gene protein product is associated with poor outcome in breast cancer. Mod Pathol 14:672-676

5. Perez-Tenorio G, Alkhori L, Olsson B, Waltersson MA, Nordenskjold B, Rutqvist LE, Skoog L, Stal O (2007) PIK3CA mutations and PTEN loss correlate with similar prognostic factors and are not mutually exclusive in breast cancer. Clin Cancer Res 13:3577-3584

6. Kirkegaard T, Witton CJ, McGlynn LM, Tovey SM, Dunne B, Lyon A, Bartlett JM (2005) AKT activation predicts outcome in breast cancer patients treated with tamoxifen. J Pathol 207:139146

7. Stal O, Perez-Tenorio G, Akerberg L, Olsson B, Nordenskjold B, Skoog L, Rutqvist LE (2003) Akt kinases in breast cancer and the results of adjuvant therapy. Breast Cancer Res 5:R37-R44

8. Berns K, Horlings HM, Hennessy BT, Madiredjo M, Hijmans EM, Beelen K, Linn SC, Gonzalez-Angulo AM, Stemke-Hale K, Hauptmann M, Beijersbergen RL, Mills GB, van de Vijver MJ, Bernards R (2007) A functional genetic approach identifies the PI3K pathway as a major determinant of trastuzumab resistance in breast cancer. Cancer Cell 12:395-402

9. Strimpakos AS, Karapanagiotou EM, Saif MW, Syrigos KN (2009) The role of mTOR in the management of solid tumors: an overview. Cancer Treat Rev 35:148-159

10. Di Cosimo S, Baselga J (2008) Targeted therapies in breast cancer: where are we now? Eur J Cancer 44:2781-2790

11. Treeck O, Wackwitz B, Haus U, Ortmann O (2006) Effects of a combined treatment with mTOR inhibitor RAD001 and tamoxifen in vitro on growth and apoptosis of human cancer cells. Gynecol Oncol 102:292-299

12. Beuvink I, Boulay A, Fumagalli S, Zilbermann F, Ruetz S, O'Reilly T, Natt F, Hall J, Lane HA, Thomas G (2005) The mTOR inhibitor RAD001 sensitizes tumor cells to DNA-damaged induced apoptosis through inhibition of p21 translation. Cell 120:747-759

13. Boulay A, Rudloff J, Ye J, Zumstein-Mecker S, O'Reilly T, Evans DB, Chen S, Lane HA (2005) Dual inhibition of mTOR and estrogen receptor signaling in vitro induces cell death in models of breast cancer. Clin Cancer Res 11:5319-5328

14. Tabernero J, Rojo F, Calvo E, Burris H, Judson I, Hazell K, Martinelli E, Ramon y Cajal S, Jones S, Vidal L, Shand N, 
Macarulla T, Ramos FJ, Dimitrijevic S, Zoellner U, Tang P, Stumm M, Lane HA, Lebwohl D, Baselga J (2008) Dose- and schedule-dependent inhibition of the mammalian target of rapamycin pathway with everolimus: a phase I tumor pharmacodynamic study in patients with advanced solid tumors. J Clin Oncol 26:1603-1610

15. Awada A, Cardoso F, Fontaine C, Dirix L, De Greve J, Sotiriou C, Steinseifer J, Wouters C, Tanaka C, Zoellner U, Tang P, Piccart M (2008) The oral mTOR inhibitor RAD001 (everolimus) in combination with letrozole in patients with advanced breast cancer: results of a phase I study with pharmacokinetics. Eur J Cancer 44:84-91

16. Baselga J, Semiglazov V, van Dam P, Manikhas A, Bellet M, Mayordomo J, Campone M, Kubista E, Greil R, Bianchi G, Steinseifer J, Molloy B, Tokaji E, Gardner H, Phillips P, Stumm M, Lane HA, Dixon JM, Jonat W, Rugo HS (2009) Phase II randomized study of neoadjuvant everolimus plus letrozole compared with placebo plus letrozole in patients with estrogen receptor-positive breast cancer. J Clin Oncol 27:2630-2637

17. Macaskill EJ, Bartlett JMS, Sabine VS, Faratian D, Renshaw L, White S, Campbell FM, Young O, Williams L, Thomas JS, Barber MD, Dixon JM (submitted) The mammalian target of rapamycin (mTOR) inhibitor everolimus (RAD001) in early breast cancer: results of a pre-operative study. Breast Cancer Res Treat

18. Dowsett M, Smith IE, Ebbs SR, Dixon JM, Skene A, A'hern R, Salter J, Detre S, Hills M, Walsh G (2007) IMPACT Trialists Group Prognostic value of Ki67 expression after short-term presurgical endocrine therapy for primary breast cancer. J Natl Cancer Inst 99:167-170

19. Jones RL, Salter J, A'hern R, Nerurkar A, Parton M, Reis-Filho JS, Smith IE, Dowsett M (2009) The prognostic significance of Ki67 before and after neoadjuvant chemotherapy in breast cancer. Breast Cancer Res Treat 116:53-68

20. Johnston SR (2008) Integration of endocrine therapy with targeted agents. Breast Cancer Res 10:S20 (suppl 4)

21. Morgensztern D, McLeod HL (2005) PI3K/Akt/mTOR pathway as a target for cancer therapy. Anticancer Drugs 16:797-803

22. Sims AH, Ong KR, Clarke RB, Howell A (2006) Highthroughout genomic technology in research and clinical management of breast cancer: Exploiting the potential of gene expression profiling: is it ready for the clinic? Breast Cancer Res 8:214

23. Bonnefoi H, Potti A, Delorenzi M, Mauriac L, Campone M, Tubiana-Hulin M, Petit T, Rouanet P, Jassem J, Blot E, Becette V, Farmer P, Andre S, Acharya CR, Mukherjee S, Cameron D, Bergh J, Nevins JR, Iggo RD (2007) Validation of gene signatures that predict the response of breast cancer to neoadjuvant chemotherapy: a substudy of the EORTC 10994/BIG 00-01 clinical trial. Lancet Oncol 8:1071-1078

24. Miller WR, Larionov A, Renshaw L, Dixon JM (2009) Gene expression profiles differentiating between breast cancers clinically responsive or resistant to letrozole. J Clin Oncol 27:1382-1387

25. Boulay A, Zumstein-Mecker S, Stephan C, Beuvink I, Zilbermann F, Haller R, Tobler S, Heusser C, O'Reilly T, Stolz B, Marti A, Thomas G, Lane HA (2004) Antitumor efficacy of intermittent treatment schedules with the rapamycin derivative RAD001 correlates with prolonged inactivation of ribosomal protein S6 kinase 1 in peripheral blood mononuclear cells. Cancer Res 64:252-261

26. O'Donnell A, Faivre S, Burris HA, Rea D, Papadimitrakopoulou V, Shand N, Lane HA, Hazell K, Zoellner U, Kovarik JM, Brock C, Jones S, Raymond E, Judson I (2008) Phase I pharmacokinetic and pharmacodynamic study of the oral mammalian target of rapamycin inhibitor everolimus in patients with advanced solid tumors. J Clin Oncol 26:1588-1595
27. Cleator SJ, Powles TJ, Dexter T, Fulford L, Mackay A, Smith IE, Valgeirsson H, Ashworth A, Dowsett M (2006) The effect of the stromal component of breast tumours on prediction of clinical outcome using gene expression microarray analysis. Breast Cancer Res 8:R32

28. Murray J, Young OE, Renshaw L, White S, Williams L, Evans DB, Thomas JS, Dowsett M, Dixon JM (2009) A randomised study of the effects of letrozole and anastrozole on oestrogen receptor positive breast cancers in postmenopausal women. Breast Cancer Res Treat 114:495-501

29. Kirkegaard T, Edwards J, Tovey S, McGlynn LM, Krishna SN, Mukherjee R, Tam L, Munro AF, Dunne B, Bartlett JM (2006) Observer variation in immunohistochemical analysis of protein expression, time for a change? Histopathology 48:787-794

30. Gentleman RC, Carey VJ, Bates DM, Bolstad B, Dettling M, Dudoit S, Ellis B, Gautier L, Ge Y, Gentry J, Hornik K, Hothorn T, Huber W, Iacus S, Irizarry R, Leisch F, Li C, Maechler M, Rossini AJ, Sawitzki G, Smith C, Smyth G, Tierney L, Yang JY, Zhang J (2004) Bioconductor: open software development for computational biology and bioinformatics. Genome Biol 5:R80

31. Ihaka R, Gentleman RR (1996) a language for data analysis and graphics. J Comput Graph Stat 5:299-314

32. Dunning MJ, Smith ML, Ritchie ME, Tavare S (2007) Beadarray: $\mathrm{R}$ classes and methods for Illumina bead-based data. Bioinformatics 23:2183-2184

33. Johnson WE, Li C, Rabinovic A (2007) Adjusting batch effects in microarray expression data using empirical Bayes methods. Biostatistics 8:118-127

34. Tusher VG, Tibshirani R, Chu G (2001) Significance analysis of microarrays applied to the ionizing radiation response. Proc Natl Acad Sci USA 98:5116-5121

35. Tibshirani R, Hastie T, Narasimhan B, Chu G (2002) Diagnosis of multiple cancer types by shrunken centroids of gene expression. Proc Natl Acad Sci USA 99:6567-6572

36. Eisen MB, Spellman PT, Brown PO, Botstein D (1998) Cluster analysis and display of genome-wide expression patterns. Proc Natl Acad Sci USA 95:14863-14868

37. Sorlie T, Perou CM, Tibshirani R, AaS T, Geisler S, Johnsen H, Hastie T, Eisen MB, van de Rijn M, Jeffrey SS, Thorsen T, Quist H, Matese JC, Brown PO, Botstein D, Eystein Lonning P, Borresen-Dale AL (2001) Gene expression patterns of breast carcinomas distinguish tumor subclasses with clinical implications. Proc Natl Acad Sci USA 98:10869-10874

38. Kitchen RR, Sabine VS, Sims AH, Macaskill EJ, Renshaw L, Thomas JS, van Hemert JI, Dixon JM, Bartlett JM (2010) Correcting for intra-experiment variation in Illumina BeadChip data is necessary to generate robust gene-expression profiles. BMC Genomics 11:134

39. Tozlu-Kara S, Roux V, Andrieu C, Vendrell J, Vacher S, Lazar V, Spyratos F, Tubiana-Hulin M, Cohen P, Dessen P, Lidereau R, Bieche I (2007) Oligonucleotide microarray analysis of estrogen receptor alpha-positive postmenopausal breast carcinomas: identification of HRPAP20 and TIMELESS as outstanding candidate markers to predict the response to tamoxifen. J Mol Endocrinol 39:305-318

40. Zhao MY, Auerbach A, D'Costa AM, Rapoport AP, Burger AM, Sausville EA, Stass SA, Jiang F, Sands AM, Aguilera N, Zhao XF (2009) Phospho-p70S6K/p85S6K and cdc2/cdk1 are novel targets for diffuse large B-cell lymphoma combination therapy. Clin Cancer Res 15:1708-1720

41. Shah SA, Potter MW, Ricciardi R, Perugini RA, Callery MP (2001) FRAP-p70s6K signaling is required for pancreatic cancer cell proliferation. J Surg Res 97:123-130

42. Chuu CP, Chen RY, Barkinge JL, Ciaccio MF, Jones RB (2008) Systems-level analysis of ErbB4 signaling in breast cancer: a laboratory to clinical perspective. Mol Cancer Res 6:885-891 
43. Sotiriou C, Pusztai L (2009) Gene-expression signatures in breast cancer. N Engl J Med 360:790-800

44. Sotiriou C, Wirapati P, Loi S, Harris A, Fox S, Smeds J, Nordgren H, Farmer P, Praz V, Haibe-Kains B, Desmedt C, Larsimont D, Cardoso F, Peterse H, Nuyten D, Buyse M, van de Vijver MJ, Bergh J, Piccart M, Delorenzi M (2006) Gene expression profiling in breast cancer: understanding the molecular basis of histologic grade to improve prognosis. J Natl Cancer Inst 98:262-272

45. Paik S, Shak S, Tang G, Kim C, Baker J, Cronin M, Baehner FL, Walker MG, Watson D, Park T, Hiller W, Fisher ER, Wickerham DL, Bryant J, Wolmark N (2004) A multigene assay to predict recurrence of tamoxifen-treated, node-negative breast cancer. $\mathrm{N}$ Engl J Med 351:2817-2826

46. Cardoso F, van't Veer L L, Rutgers E, Loi S, Mook S, PiccartGebhart MJ (2008) Clinical application of the 70-gene profile: the MINDACT trial. J Clin Oncol 26:729-735
47. Miller WR, Larionov A, Anderson TJ, Walker JR, Krause A, Evans DB, Dixon JM (2008) Predicting response and resistance to endocrine therapy: profiling patients on aromatase inhibitors. Cancer 112(3 suppl):689-694

48. Creighton CJ (2007) A gene transcription signature of the Akt/ mTOR pathway in clinical breast tumors. Oncogene 26:46484655

49. Teschendorff AE, Naderi A, Barbosa-Morais NL, Pinder SE, Ellis IO, Aparicio S, Brenton JD, Caldas C (2006) A consensus prognostic gene expression classifier for ER positive breast cancer. Genome Biol 7:R101

50. Dai H, van't Veer L, Lamb J, He YD, Mao M, Fine BM, Bernards R, van de Vijver M, Deutsch P, Sachs A, Stoughton R, Friend S (2005) A cell proliferation signature is a marker of extremely poor outcome in a subpopulation of breast cancer patients. Cancer Res 65:4059-4066 